This article was downloaded by: [US Army War College]

On: 11 September 2012, At: 20:41

Publisher: Routledge

Informa Ltd Registered in England and Wales Registered Number:

1072954 Registered office: Mortimer House, 37-41 Mortimer Street, London W1T 3J H, UK

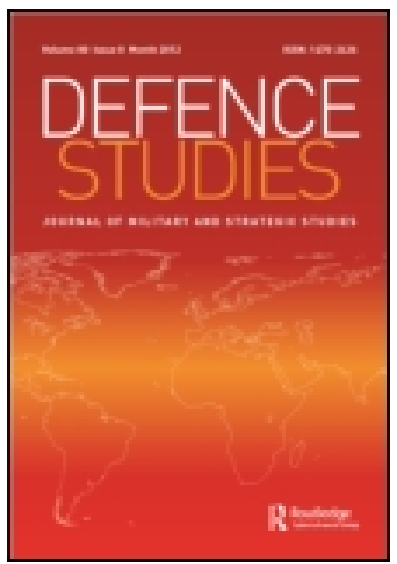

\title{
Defence Studies
}

Publication details, including instructions for authors and subscription information:

http:// www. tandfonline.com/loi/ fdef20

\section{The High Value of Targeting: A Conceptual Model for Using HVT against a Networked Enemy \\ J ohn Hardy \& Paul Lushenko}

Version of record first published: 10 Sep 2012.

To cite this article: J ohn Hardy \& Paul Lushenko (2012): The High Value of Targeting: A Conceptual Model for Using HVT against a Networked Enemy, Defence Studies, 12:3, 413-433

To link to this article: http:// dx. doi.org/ 10.1080/ 14702436.2012.703845

\section{PLEASE SCROLL DOWN FOR ARTICLE}

Full terms and conditions of use: http://www.tandfonline.com/page/ terms-and-conditions

This article may be used for research, teaching, and private study purposes. Any substantial or systematic reproduction, redistribution, reselling, loan, sub-licensing, systematic supply, or distribution in any form to anyone is expressly forbidden.

The publisher does not give any warranty express or implied or make any representation that the contents will be complete or accurate or up to date. The accuracy of any instructions, formulae, and drug doses should be independently verified with primary sources. The publisher shall not be liable for any loss, actions, claims, proceedings, demand, or costs or 
damages whatsoever or howsoever caused arising directly or indirectly in connection with or arising out of the use of this material. 


\section{The High Value of Targeting: A Conceptual Model for Using HVT against a Networked Enemy}

\section{JOHN HARDY AND PAUL LUSHENKO}

A swath of negative media attention throughout 2010 and 2011 has seen the coalition military tactic of High-Value Targeting (HVT) in Afghanistan come under intense scrutiny. ${ }^{1}$ United States Army doctrine defines a high-value target as an asset that an enemy commander requires for the completion of his mission. Within the context of Special Operations Forces (SOF), the process of HVT involves precision raids and/or airstrikes to either capture or kill specific assets or individuals required by a clandestine network to achieve its expressed aims. ${ }^{2}$ This process has been declared as ineffective in virtually all mediums for debate. The reasons offered often stem from three fundamental lines of argument: that HVT is too aggressive for counterinsurgency (COIN) operations and undermines overarching strategic goals; ${ }^{3}$ that HVT only works against hierarchical organizations and not decentralized network opponents, such as Al-Qaeda or the Haqqani Network, ${ }^{4}$ faced in current operations; and that coalition forces lack the requisite understanding of enemy organizations to successfully apply HVT. ${ }^{5}$ These lines of argument draw on assumptions about the decreasing utility of force in contemporary operations, ${ }^{6}$ the concomitant centrality of 'soft' or non-kinetic approaches to security in COIN operations, expectations of decisiveness when using force, and the elusive nature of clandestine networks. These assumptions are attractive, but they are flawed.

Matt Frankel's recent attempt to capture 'lessons learned"7 about HVT is instructive as it is the first attempt to systematically analyze

John Hardy, Strategic and Defence Studies Centre, Australian National University. Email: john.hardy@anu.edu.au

Paul Lushenko, United States Army; Department of International Relations, Australian National University. 
historical and current uses of applied targeting. However, it is impossible to learn the right lessons for future policy and practice without a comprehensive understanding of the contemporary uses of HVT. It is not 'most useful to view current campaigns through a historical lens' ${ }^{8}$ because the tactics and campaigns that Frankel uses as examples are too diverse and disparate to draw meaningful comparison. ${ }^{9}$ It is not useful to simply look to the past for answers because the HVT of the past is gone. The ghosts of the Phoenix Program ${ }^{10}$ still sell books, but they do not reflect current doctrine or practices. General (Retired) Stanley McChrystal's concept of 'industrial counterterrorism'11 came to grips with network adversaries in the mid-2000s. By 2010, Washington was modeling a new approach to network CT that is based on a greater understanding of social networks and how the components of a terrorist network operate together and independently of one another. ${ }^{12}$ Populist rhetoric reduces a complex intelligence-led tactic to a haphazardly prosecuted assassination program. In reality, HVT involves applying pressure to, targeting leverage points within, and attacking networks to disrupt and degrade their functionality. These methods of HVT complement broader strategic objectives by contributing to desired security outcomes.

This article argues that HVT contributes significant value to current operations in Afghanistan. It contends that a conceptual model of HVT can be derived from recent experiences in Iraq and Afghanistan. This paper challenges the populist notion that HVT is simply a leadership decapitation program ${ }^{13}$ intended to create a decisive outcome and promotes a model of HVT that is drawn from US Army doctrine and operational experience in Iraq and Afghanistan. ${ }^{14}$ While it reflects elements of both current doctrine and operational practice, this conceptual model also draws on a variety of disparate concepts and approaches to HVT that have not been distilled into a single, cogent framework by either scholars or practitioners. The model identifies three methods of applying force through HVT: pressuring, leveraging, and desynchronizing a network. The model then considers the impact on enemy networks and the opportunity costs on, and constraints faced by, friendly units associated with each method. The article will proceed by examining the critical conceptual flaws in the current debate of HVT and argue that a conceptual model of HVT is needed to make meaningful policy recommendations. It will then build a conceptual model for assessing HVT and present some operational considerations for applying the model to empirical research. Finally, it will recommend that this model be used in future research in the area of HVT. 


\section{The Need for a Conceptual Model of HVT}

The current debate about HVT paints the tactic in a negative light. Media outlets have asserted that HVT, and in particular so-called night raids and drone strikes, in Afghanistan are having a counterproductive impact on COIN. ${ }^{15}$ Other literature focuses on erroneous 'lessons learned' from past approaches to leadership decapitation which were attempted in a variety of situations. ${ }^{16}$ Analogies drawn from past experience are problematic when assessing HVT in current operations for three reasons. First, the tactics employed are not analogous because the intelligence and targeting cycles used in contemporary operations are different from those employed in previous operations. Second, the irregular opponents faced are increasingly complex and diverse and are not, for the most part, comparable to previous adversaries. Third, the lessons being learned ${ }^{17}$ are not observations drawn from empirical data, but assumptions being reaffirmed. The methodology of learning lessons about HVT through analogical reasoning is impeded by significant differences in the employment of HVT today and in the past.

This is symptomatic of an underlying problem: HVT is poorly understood. Worse, it is poorly conceptualized. Outside the military, HVT is almost universally conflated with strategy. ${ }^{18}$ Common claims that HVT is ineffective rely on the assumption that HVT should produce a decisive strategic outcome. This assumption fails to appreciate that HVT is a tactic and, as such, is subordinate to strategy. ${ }^{19}$ HVT cannot be conflated with strategy because it is utilized at the tactical level. The process of HVT does not identify strategic outcomes that are sought through the use of force, but is a task performed in pursuit of operational objectives dictated by a complete strategy. This fundamental misunderstanding of HVT requires redress. A coherent conceptual model for utilizing HVT against clandestine networks is needed to enable analysts to make meaningful policy recommendations. This is not simply a definitional issue. It is beneficial for the academic and policy debates to be talking about the same thing; it is essential that they are talking about the right thing.

There are four flawed assumptions in current debates about HVT. The first is that targeted, kinetic operations are counterproductive in COIN. ${ }^{20}$ This assumes that the purpose of employing HVT is to achieve goals that are not commensurate with strategic aims. The second is Frankel's claim that 'highly centralized groups will suffer a greater impact' from HVT. ${ }^{21}$ This emerges from a faulty line of reasoning that materially decentralized actors have little social hierarchy, ${ }^{22}$ when 
clandestine networks inherently rely on social networks to both operate and survive. ${ }^{23}$ The third is that coalition forces lack sufficient understanding of enemy organizational structures and local social factors to accurately judge the impact of HVT. This fails to account for the robust intelligence collection and analysis that drives HVT and the degree of collaboration between SOF and conventional forces through the use of fusion cells. ${ }^{24}$ The fourth is that effect on the enemy, decisive or otherwise, is the most central concern for utilizing HVT. ${ }^{25}$ This neglects the opportunities and constraints that influence decisions to conduct HVT.

Kinetics in COIN. Arguments that HVT is counterproductive in $\mathrm{COIN}^{26}$ create a false dichotomy between two strategies when only one is present. For example, Frankel suggests that practitioners and policymakers must observe that HVT does not "work in a vacuum. ${ }^{27}$ This lesson assumes that HVT is being employed outside of a broader strategy, yet the targeting process is subordinated to strategic objectives in both doctrine and practice. ${ }^{28}$ There is a second false dichotomy posed between kinetic and non-kinetic operations. This underpins the assumption that kinetic operations necessarily undermine the more defensive security operations held to be more consistent with COIN. However, specific kinetic strikes against clandestine networks can be used to complement conventional operations. Patrick Johnson's empirical study on leadership decapitation in COIN finds a positive correlation between the use of direct action against insurgent organizations and COIN success. ${ }^{29}$ Similarly, Bryan Price's empirical study found a positive correlation between leadership decapitation and the demise of terrorist groups. ${ }^{30}$ HVT is applied within the context of a strategy and needs to be understood in the same way. For example, HVT is employed in Afghanistan with the intent to contribute to COIN operations, not undermine them. ${ }^{31}$ In practice, the aims pursued should be the same because HVT represents one kinetic tool at the disposal of commanders pursuing a particular strategy.

Decentralized adversaries. Frankel asserts that centrally organized opponents are more susceptible to HVT than the kinds of decentralized opponents faced in current conflicts and thought to be a key characteristic of future irregular warfare. This is not necessarily true for two reasons. The first is that, decentralized networks lack the clear line of succession found in hierarchical organizations. This means that removing nodes from the network creates gaps that are potentially harder to fill, especially where niche skills or significant personal relationships are required to maintain the network. So-called 'middle-men',32 and couriers in decentralized networks are often central to the secretive 
communication that underpins the organization. Removing them can destabilize clandestine networks by compromising large sections of the organization, distancing operatives from direct guidance, and impeding organizational communication and function. The second reason is that clandestine networks often rely on powerful social connections between highly charismatic leaders to function. ${ }^{33}$ This counterposes the observable structural hierarchy of a centralized organization, such as traditional organized crime or formed military units, with a form of social or relational hierarchy ${ }^{34}$ that is present even in ostensibly decentralized networks. The experience garnered by SOF in recent operations suggests that clandestine networks are highly susceptible to HVT due to their social and communicative constitution.

Understanding of enemy organizations. When conducted within a COIN strategy HVT is employed with the same situational awareness as any other tactic. Criticism of US forces' understanding of enemy organizational dynamics is inaccurate, as COIN in Iraq and Afghanistan has necessitated a significant intelligence effort. Frankel suggests that:

Removal of leaders has a more positive lasting effect in cases where no viable successor is waiting, but the attacking force often lacks the detailed knowledge of the organizational dynamics to sufficiently judge the impact of successful kinetic operations. ${ }^{35}$

This may have been a relevant criticism of previous approaches to HVT, but it is does not account for current HVT methods in use, including the SOF targeting cycle, F3EAD (Find, Fix, Finish, Exploit, Analyze, and Disseminate), ${ }^{36}$ or the use of fusion cells to aggregate all-source intelligence to create an operational picture of the social and political environment that exists within and around the area of operations. ${ }^{37}$ HVT is not limited to generating sufficient situational awareness to engage the enemy. Rather, it extends to charting the social, economic and political networks that underpin and support clandestine networks. This process identifies key decision-makers within targeted networks and also those who support or influence them indirectly. The F3EAD targeting cycle uses significant human operator control over target selection and acquisition and then encourages the exploitation of the target and site for intelligence purposes. This exposes one potential for compromising terrorist and insurgent networks through HVT that is used at the tactical and operational levels, but underdeveloped at the conceptual level.

Effect on the enemy. Current debates about HVT rely largely on an assessment of the effects of HVT operations on enemy organizations. 
This reduction obscures the operational considerations and constraints faced by coalition forces. Problematizing HVT from an enemy-centric perspective has four key limitations. First, it does not account for the significant intelligence effort conducted by coalition forces in order to understand targeted organizations and fuel targeting cycles. Second, it does not appreciate that resource constraints might limit the number of assets that are targeted, giving a false impression of leadership targeting when high profile individuals are targeted. However, sometimes the juice isn't worth the squeeze for high risk HVT operations except where leaders have significant operational value. Third, it does not consider the opportunity costs of inaction. Efficiency in task and asset allocation may render an HVT operation the only feasible means of engaging a specific target. In circumstances where conventional interdiction is not viable, it may be more preferable to capture or kill through HVT than to allow an individual or asset to escape. Finally, it diminishes the complementarity between HVT tactics and COIN. The ability to utilize SOF and aerial assets in lieu of conventional forces better suited to conduct population security operations enables coalition forces to better perform core COIN tasks. ${ }^{38}$

In sum, these flawed assumptions prevent meaningful analysis of HVT operations as appropriate lessons cannot be learned without appropriate analytical tools. This article presents a conceptual model of HVT that addresses the flaws and omissions of previous scholarship on HVT. It also incorporates recent developments in coalition HVT practices, in particular: improved knowledge integration, ${ }^{39}$ generating and cross-referencing thousands of data points to construct a comprehensive picture of the network, acquiring holistic pattern-of-life ${ }^{40}$ data on targets, tracing logistics and money trails, identifying facilitators and non-leadership persons of interest and exploiting human and signals intelligence to fuel the targeting cycle. ${ }^{41}$ The model will present three different methods and purposes of applying HVT against clandestine networks and examine the operational considerations that contextualize the use of HVT within irregular warfare. This is important for future scholarship and policy analysis because it will enable informed assessment of HVT operations and counter the populist assumptions about HVT that undermine much existing literature.

\section{A Conceptual Model of HVT}

This conceptual model will provide a framework for analyzing HVT in irregular warfare against networked opponents. The purpose of the model is to establish a concept of HVT that can be used to assess 
current operations and policy. The model provides an end-to-end framework for assessing HVT that is informed by current doctrine and practices that relate to intelligence collection, analysis and sharing, and the HVT targeting cycle. ${ }^{42}$ It is a holistic model that is not reducible to leadership decapitation or to $\mathrm{F} 3 \mathrm{EAD}$, the targeting cycle often equated with HVT. Although F3EAD has been described as an aggressive targeting cycle, ${ }^{43}$ it is primarily the methods through which HVT is conducted and omits the operational and strategic context of targeting. In this model, HVT is situated a level of analysis above F3EAD. HVT drives the targeting cycle by linking the actions taken under F3EAD to the targeting methods applied, the intended outcomes of action, and operational conditions that circumscribe and dictate action. ${ }^{44}$

The model is focused on utilizing HVT against networked opponents in irregular warfare. For the purposes of the model, HVT is employed against clandestine or 'dark ${ }^{45}$ networks: illicit groups that conduct illegal activities and operate with a decentralized network structure to conceal the identity of their members and organization from the authorities. ${ }^{46}$ Clandestine networks rely on social networks to manage their security-efficiency trade off, which is essential to enable operatives to avoid detection and remain effective. ${ }^{47}$ Internal connectivity increases communication and functionality, but also increases the risk of detection by authorities. ${ }^{48}$ Nonetheless, clandestine networks have tasks to accomplish that necessitate the rapid and accurate exchange of information. ${ }^{49}$ Because the presence of a large number of dispersed agents reduces the overall efficiency of the organization due to unnecessary redundancy, ${ }^{50}$ clandestine networks often rely on established, trustbased social connections. ${ }^{51}$ These connections form a social hierarchy within the network that is based on 'relationships and acquaintances, reputations and fame' rather than organizational hierarchy. ${ }^{52}$ The smallworld phenomena ${ }^{53}$ in social networks accounts for links between and amongst small clusters of individuals. While social connections within cells are thought to be stronger than those among cells, ${ }^{54}$ clandestine networks may be forged on strong ties that remain mostly dormant for the purposes of operational security. ${ }^{55}$ The opposing needs for secrecy and communication can cause inactive social ties to appear weak even when they are strong. ${ }^{56}$

This undermines the orthodoxy that clandestine networks have moved 'away from controlling leaders and toward multiple, loosely linked, dispersed agents and cells, ${ }^{57}$ Such a priori reasoning regarding their decentralized nature derives from strictly materialist assumptions and discounts the social context in which clandestine networks are 
constituted and survive. ${ }^{58}$ Clandestine networks rely substantially on the social connections that unite and coordinate individual cells in accordance with organizational guidance. ${ }^{59}$ Two widely discussed examples are Al-Qaeda and Jemaah Islamiyah (JI). Al-Qaeda's various organizational structures have relied heavily on social hierarchy, with key personalities guiding and inspiring action at lower levels. ${ }^{60}$ The role of radical madrassahs in JI's social network structure indicates that crossradicalization among peer groups can forge social ties that may be more important than top-down radicalization. ${ }^{61}$ This means that while clandestine networks are increasingly decentralized in a material sense, they remain hierarchical in relational or social terms. Ostensibly decentralized social networks have hubs and nodes which can be targeted in at least three ways. HVT can pressure the network in order to harass it; leverage network elements such as 'middle-men'62 or enabling assets which facilitate communication and action; and desynchronize the network by targeting key decision-makers and figureheads to alienate operatives and leaders from one another.

Pressure. Applying pressure to a clandestine network involves harassing the organization and its members to complicate operations, force errors, and delay communication. SOF forces are used to disrupt the clandestine network and its operations. Disruption is the interruption of the enemy's operational capacity and tempo, formation or initiative. ${ }^{63}$ Practically, this means that a SOF unit targets various components of a clandestine network to desynchronize and confuse the network's support and operational activities. Applying pressure to a clandestine network is similar but not analogous to swarming: a 'seemingly amorphous' but deliberate, sustained, and coordinated series of strikes intended to disorient the enemy. ${ }^{64}$ Swarming has been described as the 'whack-a-mole' method. ${ }^{65}$ However, applying pressure enables coalition forces a degree of flexibility to concentrate, surge, or redirect combat power to disrupt a clandestine network in a piecemeal or holistic fashion. This enables SOF to gain momentum because pressuring the network can generate second-order effects such as intelligence that facilitates further HVT or conventional operations. It also shapes the battlespace for both military and non-military follow on operations. ${ }^{66}$ When used in tandem with more precise targeting, pressure can induce further disruption, colloquially termed 'squeezing' the network. Finally, pressure keeps the network on its toes by increasing the transaction costs of offensive action, operational planning and organizational communication. This can compel a network to take greater risks and expose itself to further targeting in order to remain functional. 
Leverage. In the context of HVT, leverage points are the assets that facilitate, rather than direct, action. Leverage points may include individuals with high degrees of social connection who facilitate critical communication, who possess niche skills, such as bomb-making or cryptography, or who can access or supply essential equipment. Leverage points may also include material assets, such as communications tools, explosives and ammunition, which enable clandestine networks to stage offensive operations. As such, leverage points represent 'the hub of all power and movement, on which everything depends. ${ }^{67}$ When decomposing a clandestine network into classes of actors, leverage points are often associated with task organization. ${ }^{68}$ For example, Al-Qaeda in Iraq task organized itself across a range of operational and support specialties $^{69}$ that required the services of 'facilitators, financiers, computer specialists, or bomb-makers' ${ }^{70}$ Attacking these leverage points enables SOF to attempt to destroy a clandestine network's functionality; to damage the network 'so badly that it cannot perform any function or be restored to a usable condition without being entirely rebuilt. ${ }^{71}$ This deprofessionalizes the network and imposes additional recruitment and training costs that further diminish operational capacity. ${ }^{72}$ The impact of such skills shortages on short-term offensive capacity is evidenced by Hamas between 2002 and 2005. While the number of attacks increased, the lethality of attacks decreased significantly. The capture or killing of highly skilled and experienced operatives disrupted the group's existing operations and the consequent skills deficit degraded the group's medium-term capacity to operate. ${ }^{73}$

Desynchronize. The most visible method of HVT involves capturing or killing visible and symbolic enemy leaders in order to destabilize the network and alienate organizational levels from each other. The constant removal of leadership impedes consistent guidance and coherent strategic communication, which weakens and delegitimizes leadership. Replacement leaders may be found quickly, but often lack the skills, experience, and relationships of their predecessors. Meanwhile, the network's capacity to plan, supply, and stage attacks is diminished due to an increased impetus for defensive measures and due to poor guidance from leaders to operatives. ${ }^{74}$ Networks that rely significantly on central strategic guidance to relatively autonomous cells still suffer setbacks from the targeting of highly visible or influential figures. Interference with key decision-making bodies within a network can induce power struggles and confuse organizational direction. ${ }^{75}$ It can also increase the transaction costs of maintaining organizational cohesion by forcing leaders to undertake enhanced defensive measures and restrict their 
movements to avoid detection. ${ }^{76}$ This diverts time and resources from offensive operations to precautionary measures. ${ }^{77}$ Leaders in hiding often struggle to motivate their organizations. Byman notes that after Israel's targeted killing of Hamas leader Ahmed Yassin in 2004:

Hamas appointed Rantisi as his successor. Israel promptly killed Rantisi. Hamas then announced that it has appointed a new leader but would not name him publicly: a necessary step for his survival perhaps but hardly a way to inspire the group's followers or win new converts with a show of bravery. ${ }^{78}$

Desynchronizing can be intended to both disrupt and destroy a clandestine network as internal confusion both impedes and degrades organizational capacity. In certain cases, it may also enable coalition forces to defeat an enemy network. Defeat 'occurs when an enemy force has temporarily or permanently lost the physical means or the will to fight ${ }^{79}$ and may be induced by a lack of coherent organizational purpose following the capture or killing of an influential leader. ${ }^{80}$ Price's empirical study of leadership decapitation in terrorist groups found that religious organizations were particularly susceptible to leadership targeting, possibly due to the integral role of influential figures in 'framing and interpreting organizational goals and strategies'. ${ }^{81}$ However, it is important to note that leadership targeting is not utilized as a means to victory in and of itself. $^{82}$

Although these methods of HVT have been presented as discrete items for the purposes of constructing a conceptual model, the operational reality involves utilizing all three, often simultaneously within the same area of operations against the same or other adversaries. HVT often entails a high operational tempo in order to exploit intelligence gains from SOF raids and intelligence gathering operations. Follow on HVT operations often benefit from 'reflections' within targeted networks. Reflections are spikes in communication or 'chatter' in targeted networks following coalition operations. This chatter provides information about the effect of an operation on the network and also identifies which individuals are sending and receiving information within the network, the nature of the information they are communicating, and what kind of defensive or reactionary measures they are planning. The collection of reflections also contributes to SOF situational awareness by improving understanding of a clandestine network in both horizontal (peer) and vertical (leadership) terms. For example, the targeting of Abu Musab al-Zarqawi in 2006, Abu Qaswarah in 2008, and Abu Ayub 
al-Masri in 2010 resulted from extensive pattern-of-life development of their most trusted couriers in Iraq. ${ }^{83}$

Reflections are captured through an admixture of primarily human, imagery, and signals intelligence after a particular raid or airstrike. They provide the pivot for transition to another or an additional method of HVT, allowing commanders to surge on one method, and recoil on another in order to capitalize on enemy vulnerabilities in an opportunistic manner. This has been one of the most significant aspects of utilizing HVT in coalition operations in Afghanistan in recent years. Increasing ability to exploit intelligence, rapidly transition between methods of HVT, and employ various methods of HVT simultaneously has created new opportunities for SOF operations. This has enabled commanders to better integrate SOF operations, particularly HVT, into broader conventional operations in the same geographical area. However, the ability of commanders to utilize the various methods of HVT that are available to them is not based entirely on enemy factors. While the opportunity to impact enemy networks figures into decisions to perform HVT, as well as conventional operations, there are also friendly constraints that influence commanders' determination of the desirability or suitability of employing HVT in a particular situation.

\section{Operationalizing HVT}

HVT occurs in a highly dynamic context that is shaped in roughly equal measures by enemy-related and friendly circumstances. The model of HVT presented above focuses largely on the effect that targeting operations have on enemy networks. In order to utilize this model, operational factors that influence the use of HVT must be considered. Six key factors influence the utility and efficacy of HVT for a particular situation: target utility, asset availability, operational tempo, performance, effectiveness and efficiency. Target utility, asset availability, and operational tempo relate to the cost-benefit ratio and the viability of conducting HVT. If assets can be mustered to perform a raid or strike, the return on investment must warrant the allocation of resources to the HVT operation. Performance, effectiveness, and efficiency relate to the usefulness of using SOF assets to conduct HVT. If HVT is more effective or efficient than a conventional operation, then it has merit. Alternatively, where conventional options are not viable, the opportunity costs of inaction might be great enough to spur a HVT operation rather than lose the target. 
Target utility. The decision to use HVT to capture or kill a specific target can be significantly influenced by the utility of the target. While there are varying degrees of value associated with the broad label of high value, targets can be ascribed varying levels of utility. For example, all targets of high-value are required by a clandestine network for operational success. Within the category of high-value is an embedded property: the high-payoff target. High payoff indicates that capturing or destroying the target would contribute significantly to friendly operations. ${ }^{84}$ In some circumstances the utility of pursuing a target with both high-value and high-payoff may be necessary to enable further operations, where a target with no payoff value may be deprioritized. The intention to pursue a target in order to engage an adversary may be afforded a higher or lower importance than pursuing a target in order to enable friendly operations as each can offer different returns on the investment of resources. Similarly, some targets may offer different returns. Capturing bomb-makers or weapons caches may provide an immediate tactical effect for coalition forces, while the capture of a high-profile leader might generate a large volume of intelligence as the network communicates in order to coordinate defensive responses. For example, the HVT raid into Pakistan to capture or kill Osama bin Laden may have had a significant effect on morale on both sides, but it is also likely that valuable intelligence on the network and its central communicators was gathered through site exploitation and captured in reflections.

Asset availability. HVT can be costly in terms of various material and personnel assets. The availability of intelligence collection assets is a key concern. The 'ripeness' of a particular target is contingent on the creation of relatively predictable pattern-of-life data. This derives from the effective management of various intelligence, surveillance, and reconnaissance assets, especially those relating to human, imagery, and signals intelligence. The intelligence collection process required to generate comprehensive pattern-of-life data is resource-intensive because the 'enemy is so well hidden that it takes multiple sources of intelligence to corroborate' their location. ${ }^{85}$ Other operational constraints, including force protection, logistics, communication architecture and medical support also persist. HVT operations may be limited by scarce availability of support elements to provide emergency medical assistance and casualty evacuation, transport for personnel and detainees, interoperable communications when SOF operate alongside host nation counterparts, indirect fire support, and resupply. The assets required to perform all of these functions must first be available. Then, a HVT operation must 
compete with other operations for the resources. A high resource cost that is surplus to regular demands, coupled with the intense and episodic nature of HVT, results in intermittent asset allocation to SOF conducting HVT operations. The influence of limited asset availability can be determinative when prioritizing HVT operations.

Operational tempo. The rate at which SOF operate can be measured in two ways: the frequency of operations and the intensity of the concomitant demand on resources. ${ }^{86}$ Operational tempo can offer three key indicators for commanders utilizing or considering HVT operations. The first is the intensity of the F3EAD targeting cycle. This denotes the volume and frequency of HVT operations being conducted, which is an important consideration for planning SOF and conventional operations within the same battlespace. The second is the proportion of SOF assets being used for HVT operations. This is useful in managing units, maintaining an appropriate amount of readiness for high priority contingencies, and monitoring available resources for a rapid transition between HVT methods. For example, a shift from a low volume of resourceintensive, high risk leveraging or desynchronizing raids to a high volume of less intensive pressuring operations requires available force elements. The third is the volume and type of actionable intelligence that is fueling the F3EAD cycle. This can help commanders determine whether assets have been allocated appropriately and utilized effectively and make adjustments as necessary. It can also inform measures of performance and effectiveness as information about the rate of exploitation of intelligence vulnerabilities within a targeted network can be used to improve assessments of enemy cohesion and disposition.

Performance. Measures of performance determine the tactical success of a specific HVT mission. This is predominately articulated through two rates: the rate at which SOF (a) capture or kill targets and (b) collect intelligence for further operations along a particular line of operations. ${ }^{87}$ The rate of capture or killing of targets is an important indicator of how effective SOF units have been in performing specific missions. This measure of performance is inextricably linked to the heightened operational tempo that is typically required of SOF on the basis of their resourcing, capability, and lethality. A low capture or kill rate could point to a disparity between tactics, resources, and objectives, while a high rate suggests a good match between tactics, resources, and objectives. The rate of intelligence acquisition indicates how successful HVT operations are in generating feedback loops that fuel further targeting or other operations. This is a separate consideration because even where targets are successfully pursued, only one aspect of the mission has been 
accomplished. The exploitation and analysis of intelligence is the main area of effort in the F3EAD targeting cycle. ${ }^{88}$ Operational success is important because it determines whether or not the force elements being employed are effective in completing designated missions. Performance influences decisions about the type and scale of force elements and support assets used to pursue objectives when conducting HVT.

Effectiveness. The purpose of measuring effectiveness is to assess the impact of HVT operations on targeted networks. Effectiveness is measured separately from performance because effectively conducted HVT operations may not produce desired outcomes. In order to be effective, HVT operations must attain intended objectives along a particular line of operations. Effectiveness can be measured in four key characteristics of a clandestine network: disposition, behavior, offensive capabilities, and expressed aims. Disposition is the nature or character of a clandestine network. A network that is well organized and has a strong offensive posture is qualitatively distinct from one that is weakly organized, exhausted, and mainly defensive. Behavior refers to the type of actions taken by the clandestine network. At one end of the spectrum is primarily offensive action. At the other is activity that is primarily defensive or designed to allow the network to consolidate and reorganize. Offensive capabilities are a measure of the capacity of the network to function offensively against coalition forces. Lower offensive capabilities correlate with reduced operational function and a lower level of threat, while reduced defensive capabilities can impede internal organization. Cutting across this spectrum is a consistent emphasis that networks place on recruitment and galvanizing support for near and long-term organizational objectives. Expressed aims are the stated objectives disseminated through a network's terrorist or insurgent narrative. When rhetoric reaches fever-pitch it might signify that the organization is gaining momentum. When rhetoric deemphasizes violence or expresses more moderate objectives it can suggest that the organization may be lacking support or reaching exhaustion. ${ }^{89}$

Efficiency. Aside from effectiveness, HVT can be more or less efficient than conventional operations in various circumstances. Efficiency is subordinate to effectiveness, ${ }^{90}$ meaning that an inefficient but effective HVT operation trumps any kind of ineffective tactic that could be used. However, when HVT is roughly equal in effectiveness to another option, it is incumbent on commanders to seek efficiency in task allocation. Two considerations are salient in measuring the efficiency of HVT: the opportunity costs of inaction and the relative cost of conducting the same operation through conventional means. The attempt to 
capture or kill a target through a precision raid entails the greatest risk of all available options. ${ }^{91}$ However, the potential cost of inaction may outweigh the risk of conducting HVT if the target is vitally important to the network, is highly connected or skilled, possesses critical intelligence, is particularly elusive, or has significant symbolic value. It can also be more efficient to use SOF to conduct discrete HVT operations than to employ conventional units in large scale cordon and search operations. Alternative tactics prosecuted by conventional units are often less efficient due to a lack of redundant assets, a more cumbersome planning process, lengthy authorization timeframes, and a much larger footprint. The scale of operations is particularly important due to issues such as host-nation apprehension, the proximity of a target to an official's family members or the potential media fallout from an assault like Fallujah in 2004. ${ }^{92}$ These and similar political sensitivities sometimes preclude large operations, necessitating the use of less visible means of pursuing an objective.

This combination of factors is greater than the sum of its parts. Collectively, these considerations form the basis of decisions to utilize HVT on the battlefield. The costs and benefits associated with conducting HVT, the performance and effectiveness of SOF elements, and the efficiency of HVT vis-á-vis other operations are crucial determinants of the utility and efficacy of HVT. Furthermore, they inform the application of HVT to theater-level strategies that may not appear amenable to kinetic action. Operationalizing HVT involves assessing the applicability of various methods and tactics for targeting to strategic objectives and measuring the success of HVT operations in linking tasks to outcomes. HVT can be utilized in a complementary manner by focusing kinetic action on COIN measures for success, such as population security and isolation of the insurgency from its support, ${ }^{93}$ by rapidly interdicting and exploiting the insurgent information campaign, impacting organizational function to suppress offensive action by clandestine networks, and by shaping the battlespace for conventional operations. Through a process of deconfliction, where complementarity and unity of effort are maximized, ${ }^{94}$ HVT can be tailored to contribute to a broad range of kinetic and non-kinetic operations.

\section{Conclusions}

This article has presented a conceptual model for assessing HVT that is intended to redress popular misconceptions about the utility of kinetic action in irregular war. The conceptual model provides a framework for 
analyzing HVT operations that can be used to inform future research and policy recommendations. It enables further research in measuring the utility of force in irregular conflicts against networked opponents; understanding and analyzing the organization of enemy networks; assessing the most appropriate tools for fighting networks; and, understanding the threat posed by terrorist and insurgent networks. Moreover, it provides a complex of pragmatic considerations and constraints that influence the use of HVT on the battlefield, providing a benchmark for military practitioners who will be called upon to prosecute HVT. Finally, the model correctly situates HVT within overarching strategy and identifies the potential for complementarity between kinetic and non-kinetic operations. This provides the context for assessing HVT operations that is essential in making accurate policy recommendations. Absent context, policy recommendations risk exacerbating the existing incongruence between scholarship, policy, and practice that plagues current commentary.

Rather than discounting the utility of force in irregular warfare, future research should address the ways in which force can be adapted to changing strategic environments. HVT is one example of a relatively cost-effective means of applying force to a decentralized network. It enables coalition forces to pressure, leverage or desynchronize an enemy network to advance a counterterrorism or counterinsurgency strategy, to shape the battlespace for further operations, to enable conventional operations and to complement concurrent non-kinetic operations. Despite claims that the use of force offers diminishing returns in the 21st century, HVT can be utilized effectively against decentralized networks due to their primarily social constitution. The efficacy of HVT in irregular campaigns in Iraq and Afghanistan has been contingent on, rather than impeded by, the network structures of terrorist and insurgent enemies due to the communication necessitated by their decentralized nature. Current methods of conducting HVT emphasize the adoption of network features in order to meet the challenges posed by fighting clandestine networks. HVT offers a robust and intelligence-driven targeting cycle that can be rapidly activated and used to generate otherwise unobtainable actionable intelligence. The capacity of SOF to communicate rapidly, to transition between methods of HVT and between HVT and other operations, and to exploit narrow windows of opportunity offers significant potential to assist coalition forces in 'becoming the enemy'.

HVT is a limited operational concept and should not be mistaken for a standalone foreign policy tool. It is not a strategy to be prosecuted, 
but a tactic to be performed. When conducted to achieve objectives that are subordinate to and dictated by an overriding strategy, HVT can be an effective mechanism for combating terrorism and insurgency. Future research should take this into account by using a rigorous and accurate concept of HVT. The model presented in this article will enable further scholarship on HVT operations to use a common understanding and vocabulary in the analysis of empirical data. It will also enable coherent cross-pollination of ideas between scholars, policy-makers, and practitioners in the military and intelligence communities. The disparity between scholars and practitioners has been amplified by the misunderstanding of HVT outside of the military. This model seeks to provide the conceptual tools required by future analysts, policy-makers, and commanders to make sense of HVT and its role in irregular warfare against clandestine networks. Future studies on HVT will, therefore, be able to draw meaningful policy recommendations from operational experience. Capturing lessons learned is important, but learning the right lessons is paramount.

\section{NOTES}

The views expressed in this article are those of the author and do not necessarily reflect the official policy or position of the United States Department of the Army, Department of Defense, or government.

1 Erica Gaston, Jonathan Horowitz, and Susanne Schmeidl, Strangers at the Door: Night Raids by International Forces Lose Hearts and Minds of Afghans, Regional Policy Initiative on Afghanistan and Pakistan (Washington DC and Kabul: Open Society Institute and The Liaison Office 23 Feb. 2010); Open Society Foundations and The Liaison Office, The Cost of Kill/ Capture: Impact of the Night Raid Surge on Afghan Civilians, Regional Policy Initiative on Afghanistan and Pakistan (Kabul 19 Sept. 2011).

2 Headquarters, Department of the US Army, The Targeting Process, Field Manual No. 3-60 (Washington DC: 26 Nov. 2010) p.B-1.

3 Peter Bergen and Katherine Tiedemann, 'The Drone War: Are Predators our Best Weapon or Worst Enemy?', New Republic (3 June 2009); David Kilcullen and Andrew McDonald Exum, 'Death from Above, Outrage Down Below', New York Times (16 May 2009).

4 Dan Rassler and Vahid Brown, The Haqqani Nexus and the Evolution of Al-Qa'ida, Harmony Program (New York: Combating Terrorism Center, West Point 14 July 2011).

5 Matt Frankel, 'The ABCs of HVT: Key Lessons from High Value Targeting Campaigns against Insurgents and Terrorists', Studies in Conflict and Terrorism 34/1 (Jan. 2011) pp.26-7.

6 Rupert Smith, The Utility of Force: The Art of War in the Modern World (New York: Vintage Books 2008); Isabelle Duyvesteyn, 'Great Expectations: The Use of Armed Force to Combat Terrorism', Small Wars and Insurgencies 19/3 (Sept. 2008) pp.328-51.

7 Frankel, 'The ABCs of HVT' (note 5) pp.17-8.

8 Ibid. p.18.

9 Frankel's dataset consists of 12 historical and 8 recent examples of states using techniques that might be loosely described as similar to HVT against a variety of terrorist and insurgent actors in contexts ranging from conventional war to domestic policing. However, the examples are inconsistent in terms of the conflict situation (where there is a conflict), the military or police actors involved, the techniques employed and the types of actors targeted. See Ibid. (note 5) pp.17-8, 30. 
10 Mark Moyar, Phoenix and the Birds of Prey (Lincoln: Univ. of Nebraska Press 1997); Stuart A Herrington, Stalking the Vietcong: Inside Operation Phoenix: A Personal Account (New York: Ballantine Books 2004).

11 Mark Urban, Task Force Black: The Explosive True Story of the Secret Special Forces War in Iraq (New York: St Martin's Press 2011) p.91.

12 Eric Schmitt and Thom Shanker, Counterstrike: The Untold Story of America's Secret Campaign against Al Qaeda (New York: Times Books 2011) pp.180-94.

13 Jenna Jordan, 'When Heads Roll: Assessing the Effectiveness of Leadership Decapitation', Security Studies 18/4 (2009) pp.719-55; Frankel, 'The ABCs of HVT' (note 5).

14 Captain Lushenko, US Army, has served as the J2 (Intelligence Officer) of a Joint Special Operations Task Force on multiple tours to Iraq and Afghanistan.

15 Bergen and Tiedemann, 'The Drone War' (note 3); Gaston, Horowitz, and Schmeidl, Strangers at the Door (note 1); Kilcullen and Exum, 'Death from above, Outrage Down Below' (note 3); Open Society Foundations and The Liaison Office, The Cost of Kill/Capture (note 1).

16 Jordan, 'When Heads Roll' (note 13); Frankel, 'The ABCs of HVT' (note 5).

17 Frankel, 'The ABCs of HVT' (note 5).

18 For example, see Rohan Gunaratna, Inside Al Qaeda: Global Network of Terror (New York: Berkley 2003) p.233; John Walcott, 'Killing al-Qaeda's Middle Managers May Be Key to its Destruction', Bloomberg (26 Oct. 2011), available at <http://mobile.bloomberg.com/ news/2011-10-26/killing-al-qaeda-s-middle-managers-may-be-key-to-its-destruction $>$.

19 Carl von Clausewitz, On War, ed.and trans. Michael E. Howard and Peter Paret (Oxford: OUP 1976); Colin S. Gray, Modern Strategy (Oxford: OUP 1999); Colin S. Gray, 'Strategic Thoughts for Defence Planners', Survival 52/3 (June 2010) pp.159-78; Joseph C. Wylie, Military Strategy: A General Theory of Power Control (New Brunswick, NJ: Rutgers UP 1967); Harry R. Yarger, Strategy and the National Security Professional: Strategic Thinking and Strategy Formulation in the Twenty First Century (Westport, CT: Praeger Security International 2008).

20 Bergen and Tiedemann, 'The Drone War' (note 3); Kilcullen and Exum, 'Death from Above, Outrage Down Below' (note 3).

21 Bergen and Tiedemann, 'The Drone War' (note 3); Kilcullen and Exum, 'Death from Above, Outrage Down Below' (note 3).

22 Cynthia Stohl and Michael Stohl, 'Secret Agencies: The Communicative Constitution of a Clandestine Organization', Organization Studies 32/9 (Sept. 2011) pp.1197-215.

23 Jorg Raab and H. Brinton Milward, 'Dark Networks as Problems', Journal of Public Administration Research and Theory 13/4 (Oct. 2003) pp.413-39; Hu Daning, Siddharth Kaza, and Hsinchun Chen, 'Identifying Significant Facilitators of Dark Network Evolution', Journal of the American Society for Information Science and Technology 60/4 (Jan. 2009) pp.655-65; Siddarth Kaza, Hu Daning, and Chen Hsinchun, 'Dynamic Social Network Analysis of a Dark Network: Identifying Significant Facilitators' (Intelligence and Security Informatics Conference, New Brunswick, New Jersey 23-24 May 2007).

24 Paul Lushenko, "Partnership 'Till It Hurts": The Use of Fusion Cells to Establish Unity of Effort between SOF (Yin) and Conventional Forces (Yang)', Small Wars Journal (20 May 2010), available at <http://smallwarsjournal.com/blog/journal/docs-temp/438lushenko.pdf $>$.

25 Daniel Byman, 'Do Targeted Killings Work?', Foreign Affairs 85/2 (March/April 2006) pp.95-111.

26 Bergen and Tiedemann, 'The Drone War' (note 3); Kilcullen and Exum, 'Death from Above, Outrage Down Below' (note 3).

27 Frankel, 'The ABCs of HVT' (note 3) p.20.

28 Michael T. Flynn, Rich Juergens, and Thomas L. Cantrell, 'Employing ISR: SOF Best Practices', Joint Forces Quarterly, 50 (July 2008) p.57. See also Headquarters, Department of the US Army, The Targeting Process (note 2) p.B-1.

29 Patrick Johnston, 'Does Decapitation Work? Assessing the Effectiveness of Leadership Targeting in Counterinsurgency Campaigns', International Security 36/4 (Spring 2012) pp.47-79. 
30 Bryan C. Price, 'Targeting Top Terrorists: How Leadership Decapitation Contributes to Counterterrorism', International Security 36/4 (Spring 2012) pp.9-46.

31 Stanley A. McChrystal, 'Becoming the Enemy: To Win in Afghanistan, We Need to Fight More Like the Taliban', Foreign Policy 185 (March/April 2011) pp.66-70

32 Peter Neumann, Ryan Evans, and Raffaello Pantucci, 'Locating Al Qaeda's Center of Gravity: The Role of Middle Managers', Studies in Conflict and Terrorism 34/11 (Nov. 2011) pp.825-42.

33 Farwaz A. Gerges, The Rise and Fall of Al-Qaeda (New York: Oxford UP 2011) p.112.

34 Roy Lindelauf, Peter Borm, and Herbert Hamers, Understanding Terrorist Network Topologies and Their Resilience against Disruption, Discussion Paper No. 85 (Tilburg, Nederlands: CentER, Tilburg University 4 Nov. 2009); Stohl and Stohl, 'Secret Agencies' (note 22); Kaza, Daning, and Hsinchun, 'Dynamic Social Network Analysis of a Dark Network' (note 23).

35 Frankel, 'The ABCs of HVT' (note 5).

36 According to FM 3-60: 'F3EAD features massed, persistent reconnaissance, or surveillance cued to a powerful and decentralized all-source intelligence apparatus to find a' high value target. 'The exploit and analyze steps are often the main effort of F3EAD because these steps provide insight into the enemy's network and may open new lines of operation.' Headquarters, Department of the US Army, The Targeting Process (note 2) p.B-1. See also Flynn, Juergens, and Cantrell, 'Employing ISR' (note 28) p.57.

37 Christopher J. Lamb and Evan Munsig, Secret Weapon: High-Value Target Teams as an Organizational Innovation, Strategic Perspectives 4 (Washington DC: Institute for National Strategic Studies March 2011).

38 United States Department of the Army, US Army and Marine Corps Counterinsurgency Field Manual, FM 3-24, MCWP 3-33.5 (Chicago and London: Univ. of Chicago Press 2007). See also: David H. Petraeus, 'Learning Counterinsurgency: Observations from Soldiering in Iraq', Military Review (Jan/Feb 2006) pp.2-12; Kalev Sepp, 'Best Practices in Counterinsurgency', Military Review (May/June 2005) pp.8-12.

39 Chad C. Serena, A Revolution in Military Adaptation: The US Army in the Iraq War (Washington DC: Georgetown UP 2011) pp.115-7. See also Paul M. Salmon, Neville A. Stanton, Guy H. Walker, and Daniel P. Jenkins, Distributed Situational Awareness: Theory, Measurement and Application to Teamwork (Farnham, UK: Ashgate 2009).

40 Pattern of life analysis is 'connecting the relationships between places and people by tracking their patterns of life. While the enemy moves from point to point, reconnaissance or surveillance tracks and notes every location and person visited. Connections between those sites and persons to the target are built, and nodes in the enemy's network emerge.' Headquarters, Department of the US Army, The Targeting Process (note 2) p.B-3

41 Lushenko, "Partnership 'Till It Hurts"” (note 24) p.9.

42 Flynn, Juergens, and Cantrell, 'Employing ISR' (note 28).

43 Ibid.

44 Although the US Army's official targeting methodology, D3A - decide, detect, deliver, assess - also attempts to nest F3EAD as a current tactic, technique, and procedure, it is focused on tactical and operational concerns, rather than the strategic and policy context of concern for scholars and policy analysts. See Headquarters, Department of the US Army, The Targeting Process (note 2) p.B-2

45 Raab and Milward, 'Dark Networks as Problems' (note 23).

46 Andrew R. Molnar, Undergrounds in Insurgent, Revolutionary and Resistance Warfare (Washington DC: The Special Operations Research Office, The American Univ. 1963) pp.23-4. Ferdinand Otto Miksche, Secret Forces: The Technique of Underground Movements (London: Faber 1952).

47 Carlo Morselli, Cynthia Giguere, and Katia Petit, 'The Efficiency/Security Trade-Off in Criminal Networks', Social Networks 29/1 (2007) pp.143-53; Jacob N. Shapiro, 'The Terrorist's Challenge: Security, Efficiency, Control', Center for International Security and Cooperation, Stanford University (26 April 2007), available at <http://igcc3.ucsd. edu/pdf/Shapiro.pdf $>$. 
48 G. H. McCormick and G. Owen, 'Security and Coordination in a Clandestine Organization', Mathematical and Computer Modelling 31/6-7 (March/April 2000) p.190.

49 Wayne E. Baker and Robert R. Faulkner, 'The Social Organization of Conspiracy: Illegal Networks in the Heavy Electrical Equipment Industry', American Sociological Review 58/6 (Dec. 1993) p.844.

50 Nasrullah Memon and Henrik Larsen, 'Practical Algorithms for Destabilizing Terrorist Networks', in Practical Algorithms for Destabilizing Terrorist Networks, ed. Sharad Mehrotra, et al., Lecture Notes in Computer Science (Berlin and Heidelberg: Springer 2006) p.393. McCormick and Owen, 'Security and Coordination in a Clandestine Organization' (note 48) p.190.

51 Valdis E. Krebs, 'Mapping Networks of Terrorist Cells', Connections 24/3 (2002) pp.49-51.

52 McChrystal, 'Becoming the Enemy'(note 31) p.68.

53 Duncan J. Watts, 'Networks, Dynamics, and the Small-World Phenomenon', American Journal of Sociology 105/2 (Sept. 1999) pp.493-527.

54 Albert-Lászlœ Barabasi, Linked: How Everything Is Connected to Everything Else and What It Means (New York: Plume 2003) pp.41-4.

55 Krebs, 'Mapping Networks of Terrorist Cells' (note 51) p.49.

56 Mark S. Granovetter, 'The Strength of Weak Ties', American Journal of Sociology 78/6 (May 1973) pp.1360-80; Roy Lindelauf, Peter Borm, and Herbert Hamers, 'On Heterogeneous, Covert Networks', in On Heterogeneous, Covert Networks, ed. Nasrullah Memon et al. (Norderstedt, Germany: Springer-Verlag/Wein 2009) pp.218-9; Roy Lindelauf, Peter Borm, and Herbert Hamers, 'The Influence of Secrecy on the Communication Structure of Covert Networks', Social Networks 31/2 (May 2009) p.127.

57 Stohl and Stohl, 'Secret Agencies' (note 22) p.1198. See also Marc Sageman, Understanding Terror Networks (Philadelphia, PA: Pennsylvania UP 2004).

58 Keith G. Provan and Patrick Kenis, 'Modes of Network Governance: Structure, Management, and Effectiveness', Journal of Public Administration Research and Theory 18/2 (April 2008) pp.229-52; Alexander Gutfraind, 'Understanding Terrorist Organizations with a Dynamic Model', in Understanding Terrorist Organizations with a Dynamic Model, ed. Nasrullah Memon et al. (Norderstedt, Germany: Springer-Verlag/Wein 2009); Nasrullah Memon, David L. Hicks, Henrik Legind Larsen, and Muhammad Aslam Uqaili, 'Understanding the Structure of Terrorist Networks', International Journal of Business Intelligence and Data Mining 2/4 (2007) pp.401-25.

59 Lindelauf, Borm, and Hamers, 'The Influence of Secrecy on the Communication Structure of Covert Networks' (note 34); McCormick and Owen, 'Security and Coordination in a Clandestine Organization' (note 48); Stohl and Stohl, 'Secret Agencies' (note 22).

60 Gerges, The Rise and Fall of Al-Qaeda (note 30); Kaza, Daning, and Hsinchun, 'Dynamic Social Network Analysis of a Dark Network' (note 23); Rohan Gunaratna and Aviv Oreg, 'Al Qaeda's Organizational Structure and Its Evolution', Studies in Conflict and Terrorism 33/12 (Dec. 2010) pp.1043-78.

61 Justin Magouirk and Scott Atran, 'Jemaah Islamiyah's Radical Madrassah Networks', Dynamics of Asymmetric Conflict 1/1 (March 2008) pp.25-41; Stuart Koschade, 'A Social Network Analysis of Jemaah Islamiyah: The Applications to Counterterrorism and Intelligence', Studies in Conflict \& Terrorism 29/6 (June 2006) pp.559-75.

62 Neumann, Evans, and Pantucci, 'Locating Al Qaeda's Center of Gravity' (note 32).

63 Headquarters, Department of the US Army, Combat Tactics, Field Manual No. 3-90 (Washington DC 4 July 2001) pp.B-16-7.

64 John Arquilla and David Ronfeldt, 'The Advent of Netwar (Revisited)', in The Advent of Netwar (Revisited), ed. John Arquilla and David Ronfeldt (Santa Monica, CA: RAND Corporation 2001) pp.1-25.

65 Flynn, Juergens, and Cantrell, 'Employing ISR' (note 28) p.59.

66 Barton Gellman, 'William McRaven: The Admiral', Time, 14 Dec. 2011.

67 Neumann, Evans, and Pantucci, 'Locating Al Qaeda's Center of Gravity' (note 32). See also Doonella H. Meadows, Thinking in Systems: A Primer (White River Junction, VT: Chelsea Green Publishing 2008) p.145. 
68 Paul K. Davis and Brian Michael Jenkins, 'A System Approach to Deterring and Influencing Terrorists', Conflict Management and Peace Science 21/1 (Feb. 2004) p.8.

69 Austin Long, 'Assessing the Success of Leadership Targeting', CTC Sentinel 3/11-12 (Nov. 2010) p.20.

70 Frankel, 'The ABCs of HVT' (note 5) p.27.

71 Headquarters, Department of the Army, Combat Tactics (note 63) pp.B-15-B-16.

72 Alex S. Wilner, 'Targeted Killings in Afghanistan: Measuring Coercion and Deterrence in Counterterrorism and Counterinsurgency', Studies in Conflict and Terrorism 33/4 (April 2010) p.312.

73 Byman, 'Do Targeted Killings Work?' (note 25) pp.103-4.

74 Wilner, 'Targeted Killings in Afghanistan' (note 72) p.312; Long, 'Assessing the Success of Leadership Targeting' (note 69).

75 Gal Luft, 'The Logic of Israel's Targeted Killing', Middle East Quarterly 10/1 (Winter 2003) pp.3-13.

76 Boaz Goaner, The Counter-Terrorism Puzzle: A Guide for Decision Makers (New Brunswick, NJ: Transaction 2005) p.128. See also Byman, 'Do Targeted Killings Work?' (note 25).

77 Alex S. Wilner, The Best Defence Is a Terrific Offence: Four Approaches to Countering Modern Terrorism, AIMS Commentary (Halifax, NS: Atlantic Institute for Market Studies 3 July 2007) p.5.

78 Byman, 'Do Targeted Killings Work?' (note 25) p.104.

79 Headquarters, Department of the US Army, Combat Tactics (note 63) p.B-15.

80 Gunaratna notes that delegitimizing leaders should be an integral component of coalition counterterrorism strategies. See Gunaratna, Inside Al Qaeda (note 18) p.371.

81 Price 'Targeting Top Terrorists' (note 30) p.44

82 Gellman, 'William McRaven' (note 66).

83 John F. Burns, 'US Strike Hits Insurgent at Safehouse', New York Times (8 June 2006); Bill Roggio, 'US Forces Kill al Qaeda in Iraq's Deputy Commander', The Long War Journal (15 Oct. 2008), available at <www.longwarjournal.org/archives/2008/10/us forces kill_al_qa_1.php>; Waleed Ibrahim, 'Al Qaeda's Two Top Iraq Leaders Killed in Raid', Reuters (19 April 2010), available at < http://uk.reuters.com/article/2010/04/19/uk-iraq-violence-alqaeda-idUKTRE63I3KS20100419>.

84 Headquarters, Department of the US Army, The Targeting Process (note 2) p.B-1

85 Flynn, Juergens, and Cantrell, 'Employing ISR' (note 28) p.57.

86 McChrystal, 'Becoming the Enemy' (note 31) p.70.

87 Headquarters, Department of the US Army, The Targeting Process (note 2) p.B-7

88 Ibid. Flynn, Juergens, and Cantrell, 'Employing ISR' (note 28) p.57.

89 Gerges, The Rise and Fall of Al-Qaeda (note 33) pp.84-103.

90 Yarger, Strategy and the National Security Professional (note 19).

91 William H. McRaven, Spec Ops: Case Studies in Special Operations Warfare: Theory and Practice (New York: Presidio Press 1996).

92 Dick Camp, Operation Phantom Fury: The Assault and Capture of Fallujah, Iraq (Minneapolis, MN: Zenith Press 2009).

93 United States Department of the Army, Counterinsurgency Field Manual (note 38).

94 Ibid. See also Shanthie Mariet D'Souza, "Unity of Effort": The Missing Link in the Afghan Counter-Insurgency Campaign', Strategic Analysis 32/5 (Sept. 2008) pp.855-78.

95 McChrystal, 'Becoming the Enemy' (note 31). 